\section{Gegenwind für regulatorische T-Zellen?}

\author{
Die allergologische Forschung befasst sich zurzeit intensiv mit \\ regulatorischen T-Zellen. Die Hypothese, wonach ein Funktionsdefizit \\ dieser Zellen für Allergien verantwortlich ist, sollte angesichts einer \\ neuen Studie jedoch hinterfragt werden.
}

\begin{abstract}
E in Forscherteam aus Florenz reinigc te und kultivierte aus peripherem humanen Blut regulatorische T-Zellen (Treg) sowie T-Helfer-(TH-)Zellen. Das Blut stammte von sechs gesunden Probanden sowie von sechs Atopikern, die gegen das Hausstaubmilbenallergen Der $\mathrm{p} 1$ sensibilisiert waren. Die beiden T-Zell-Arten wurden mit dendritischen Zellen inkubiert, die entweder mit dem Allergen Der p 1, mit dem bakteriellen Antigen Streptokinase oder mit keinem Antigen beladen waren.
\end{abstract}

Interessanterweise bot sich beim Experiment mit den T-Zellen der Probanden mit Hausstaubmilbenallergie ein analoges Bild: Auch hier waren die Treg - bei Kontakt mit Der-p-1-beladenen dendritischen Zellen - in der Lage, die Vermehrung entsprechender spezifischer TH-Zellen deutlich zu unterdrücken.

Fazit: Atopiker verfügen sehr wohl über funktionstüchtige regulatorische T-Zellen. Diese können in Anwesenheit antigenpräsentierender Zellen spezifische T-Helfer-Zellen in ihrer Proliferation hemmen. Suppression der TH-Population. Trugen die dendritischen Zellen das Streptokinaseantigen, wirkten die Treg nur dann inhibitorisch, wenn sie durch monoklonale Antikörper unspezifisch aktiviert worden waren.
Maggi L et al. Demonstration of circulating allergen-specific $C D 4^{+} \mathrm{CD} 25^{\text {high }}$

Foxp $3^{+}$T-regulatory cells in both nonatopic and atopic individuals. J Allergy Clin Immunol 2007; 120: 429-36

\title{
Was bringt Immuntherapie+Omalizumab?
}

\author{
Die Annahme, dass die Gabe von Anti-IgE-Antikörpern die Wirkung \\ einer Hyposensibilisierung erhöht, scheint plausibel. Welche kon- \\ kreten immunologischen Effekte lassen sich hier nachweisen?
}

E in britisch-amerikanisches Forscherteam rekrutierte Patienten mit einer Sensibilisierung gegen beifußblättriges Traubenkraut (Ragweed) und teilte sie in vier Gruppen ein. Die erste Gruppe erhielt über zwölf Wochen eine spezifische Immuntherapie (SIT) mit Traubenkrautallergen zusammen mit dem AntiIgE-Antikörper Omalizumab. In Gruppe zwei erfolgte nur eine SIT, die dritte Gruppe wurden ausschließlich mit Omalizumab behandelt. Patienten in Gruppe vier bekamen schließlich nur Plazebopräparate verabreicht.

Um die Bindungsstärke der IgE-Antikörper an das Allergen messen zu können, wählten die Forscher folgenden Ansatz: Aus dem Serum von Probanden mit hohem spezifischen IgE („Indikatorserum") extrahierten sie diese Antikörper und inkubierten sie zusammen mit Traubenkrautallergenen. Die entstandenen Allergen-Antikörper-Komplexe wurden dann mit gentechnisch veränderten $\mathrm{B}$ Zellen inkubiert, die den IgE-Rezeptor
FceRII (CD23) trugen. Zuletzt erfolgte die Zugabe von Anti-IgE-FluoresceinIsothiocyanat, um die gebundenen $\mathrm{IgE}$ Antikörper zu quantifizieren.

Unter Zugabe von Patientenserum aus den unterschiedlichen Studienarmen zum Indikatorserum zeigten sich sechs Wochen nach Beendigung der Hyposen-

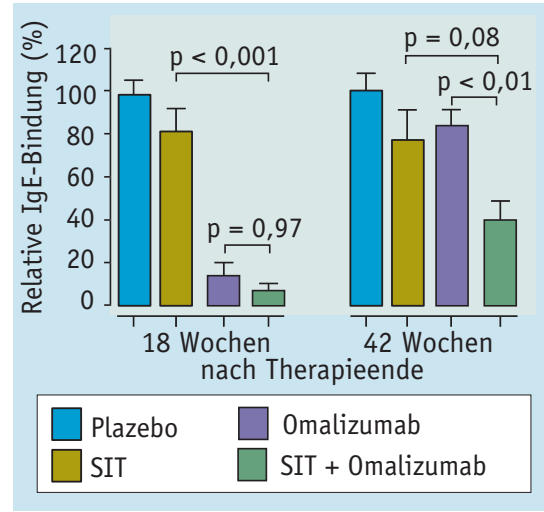

Die Inhibiton der IgE-Bindung durch Serum ist langfristig bei der Kombination von SIT mit Omalizumab am höchsten. sibilisierung folgende Ergebnisse: Die IgE-Bindungsstärke war unter Plazebo weitgehend unverändert geblieben. Im Serum von ausschließlich mit SIT behandelten Patienten war eine Abschwächung der Bindungsintensität zu beobachten. Unter Omalizumab - sowohl als Monotherapie als auch in Kombination mit der SIT - war die Bindung von IgE zunächst überhaupt nicht nachweisbar. Im Langzeitverlauf bis zu 42 Wochen nach Beendigung der SIT nahm die Bindungsstärke außer in der Plazebogruppe wieder zu. Die schwächste Bindung lag in der Gruppe vor, die mit SIT und Omalizumab behandelt worden war. Allergenspezifisches IgG4 war nur in den beiden SIT-Gruppen nachweisbar.

Fazit: Kurzfristig hemmt die Gabe von Anti-IgE-Antikörpern die Bindung von Allergenen an spezifische IgE-Rezeptoren am stärksten. Langfristig zeigt die Kombination aus SIT und Omalizumab die effektivste IgE-Inhibiton.

Klunker $\mathbf{S}$ et al. Combination treatment with omalizumab and rush immunotherapy for ragweed-induced allergic rhinitis: inhibition of IgE-facilitated allergen binding. J Allergy Clin Immunol 2007; 120: 688-95 